\title{
Can Gridded Precipitation Data and Phenological Observations Reduce Basis Risk of Weather Index-Based Insurance?
}

\author{
TOBIAS DALHAUS AND ROBERT FingER \\ Agricultural Economics and Policy Group, D-MTEC, ETH Zürich, Zurich, Switzerland
}

(Manuscript received 8 February 2016, in final form 14 July 2016)

\begin{abstract}
Adverse weather events occurring at sensitive stages of plant growth can cause substantial yield losses in crop production. Agricultural insurance schemes can help farmers to protect their income against downside risks. While traditional indemnity-based insurance schemes need governmental support to overcome market failure caused by asymmetric information problems, weather index-based insurance (WII) products represent a promising alternative. In WII the payout depends on a weather index serving as a proxy for yield losses. However, the nonperfect correlation of yield losses and the underlying index, the so-called basis risk, constitutes a key challenge for these products. This study aims to contribute to the reduction of basis risk and thus to the addition of risk-reducing properties of WII. More specifically, the study tests whether grid data for precipitation (vs weather station data) and phenological observations (vs fixed time windows for index determination) that are provided by public institutions can reduce spatial and temporal basis risk and thus improve the performance of WII. An empirical example of wheat production in Germany is used.

No differences were found between using gridded and weather station precipitation, whereas the use of phenological observations significantly increases expected utility. However, even if grid data do not yet reduce basis risk, they enable overcoming several disadvantages of using station data and are thus useful for WII applications. Based on the study's findings and the availability of these data in other countries, a massive potential for improving WII can be concluded.
\end{abstract}

\section{Introduction}

Crop production is exposed to a variety of risks that increase the volatility of farm profits (e.g., Hardaker et al. 2004). In particular, the high variability of weather is of relevance for agricultural producers, encouraging the development of efficient risk management tools. In this context agricultural insurance schemes traditionally play a major role in many countries (Glauber 2013). To overcome problems caused by asymmetric information associated with indemnity-based insurance solutions, index insurance products have been suggested as an alternative (Turvey 2001). These insurance solutions also

Supplemental information related to this paper is available at the Journals Online website: http://dx.doi.org/10.1175/ WCAS-D-16-0020.s1.

Corresponding author address: Tobias Dalhaus, Agricultural Economics and Policy Group, D-MTEC, ETH Zürich Sonneggstrasse 33, 8092 Zurich, Switzerland.

E-mail: tdalhaus@ethz.ch have been discussed as a viable strategy for adapting to increasing climatic risks caused by climate change (Patt et al. 2009). In contrast to traditional insurance products, the payout of index or parametric insurances does not depend on actual losses but on the performance of a predefined index or trigger value. Weather indices, such as the sum of precipitation in a certain accumulation period, are used as underlying of the index [see, e.g., Leblois and Quirion (2013) for an overview]. In this example, a payout occurs if a strike level of the underlying precipitation value is undercut or exceeded, depending on the contract design. To allow for the efficient reduction of on-farm losses, the chosen index must adequately describe on-farm results (Woodard and Garcia 2008). The remaining basis risk-that is, the discrepancy between the losses experienced by the farmer and the indemnity of the index insurance-is one of the key challenges for acceptance by farmers (e.g., Elabed et al. 2013). Although several index insurance products are available in the market, basis risk remains the biggest hurdle to overcome (see, e.g., Turvey and McLaurin 2012). More specifically, three sources of basis risk are 
important. First, the design basis risk describes the fact that the index value does not include all the relevant information for predicting the targeted farm-level yield. Second, spatial basis risk is caused by the distance between the point of index measurement (e.g., weather station) and the farm's location (Leblois et al. 2014b; Ritter et al. 2014). Third, temporal basis risk captures the imperfect choice of the time frame for index determination (Deng et al. 2007; Díaz-Nieto et al. 2010).

In our analysis we will build upon various contributions to reduce design risk that have been suggested (e.g., Pelka and Musshoff 2013; Conradt et al. 2015a). In this study, we further aim to present novel approaches to reduce both spatial and temporal basis risk. We synthesize the different approaches used to reduce spatial and temporal basis risk in a literature review presented in the subsequent section. The approaches used so far provide promising and innovative ways to reduce basis risk effectively. However, the suggestions made in earlier research are usually both considerably complex and costly. Thus, these approaches limit acceptability by farmers and insurance providers. To overcome these problems, we propose the use of publicly provided weather grid data and regional plant growth observations in weather index-based insurance (WII) design.

Our empirical results show that grid data do not outperform station data in terms of the reduction of basis risks. Yet, the use of grid data can facilitate index insurance design. The use of phenological observations is found to significantly reduce basis risk and thus increase farmers' expected utility. The remainder of this paper is structured as follows. We first present a literature review on strategies to cope with spatial and temporal basis risk. Second, the conceptual background of index design, option pricing, expected utility, and hypotheses tests is presented. Third, the datasets for weather, phenology, and yields are described. Fourth, we present our results. Finally, results are discussed and concluding remarks are presented.

\section{Literature review}

Regarding spatial basis risk, for instance, Woodard and Garcia (2008) suggest using weather data obtained from a station as close as possible to the farm. This is of particular relevance for precipitation indices, because the correlation between the index and losses quickly declines with increasing distance (Odening et al. 2007; Norton et al. 2012). To overcome problems with low densities of weather stations, other authors (Heimfarth and Musshoff 2011; World Bank 2013) suggest either interpolating weather station data to on-farm locations or creating a portfolio of contracts from different stations around the farm. For instance, kriging techniques have been used to estimate on-farm rainfall based on nearby weather stations' data (Paulson et al. 2010) and to explain the relationship between rainfall at the two locations (Norton et al. 2015). Along these lines, the World Bank (2013) used a model to interpolate station data to a grid of $9 \mathrm{~km} \times 9 \mathrm{~km}$ resolution covering Guatemala and Honduras. Other studies suggest creating a portfolio of several weather options based on the data from different weather stations using a geographic cross hedging effect (Berg and Schmitz 2008; Woodard and Garcia 2008; Ritter et al. 2014). Norton et al. (2012) detected that weighting this portfolio by geographical parameters, such as longitude, latitude, altitude, or distance, further decreases spatial basis risk.

Besides spatial basis risk arising from imprecise weather information, temporal basis risk mainly results from choosing index measurement time windows that are imperfect for two reasons. First, the chosen time windows that are based on general calendrical definitions - that is, choosing the cumulative rainfall in a specific month-are just proxies for critical vegetation periods. In reality, these growing phases vary across space and time. Only a few studies have incorporated growing seasons explicitly (e.g., Kapphan et al. 2012; Leblois et al. 2014b; Conradt et al. 2015b; Kumar et al. 2016). While Kapphan et al. (2012) extracted information on vegetation phases from a crop model, Leblois et al. (2014a) and Conradt et al. (2015b) used growing degree days to specify vegetation periods. Kumar et al. (2016) identified heat-sensitive growth stages from experimental data based on observed phenological phases. Second, the start and end dates of these windows of index measurement are usually fixed; that is, they are identical in every year (e.g., start and end dates of months). This choice ignores the fact that the timing of single-growth stage periods varies from year to year. These fixed time windows are, however, chosen in all studies on weather index insurances so far. ${ }^{1}$ As an exception, Conradt et al. (2015b) used flexible weather index definitions based on vegetation periods defined using growing degree days (GDD), allowing index measurement windows to be specially suited to the vegetation phase and to vary from year to year. This flexible index definition was found to be superior to a fixed index definition (Conradt et al. 2015b). However, the definition of vegetation phases based on GDD faces several challenges, for example, that assumptions must

\footnotetext{
${ }^{1}$ Note that some studies do vary the insurance period, however, only considering shifts in the whole growing cycle (see, e.g., Leblois et al. 2014a,b).
} 
be made on the occurrence of vegetation periods based on GDD across various crops and varieties used, and that precise knowledge of sowing dates might be required (Conradt et al. 2015b).

All of the described approaches to reduce temporal and geographical basis risk imply a decrease in the traceability and an increase of the complexity of the weather index insurance. Furthermore, holding several contracts to reduce geographical basis risk increases transaction costs (Ritter et al. 2014). Along these lines, Odening and Shen (2014) stated that increasing the complexity of index insurance in order to reduce basis risk counteracts market acceptance due to the demand for easily understandable products (Odening et al. 2007). Therefore, Leblois et al. (2014a, p. 532) suggest using "the most transparent index among indices reaching similar outcomes" (see also Patt et al. 2009). In contrast, WII uptake is also limited due to basis risk (Gine et al. 2008; Elabed et al. $2013^{2}$ ). Thus, there is a clear trade-off between index complexity and basis risk reduction potential. In addition, weather portfolios (or more general weather processing) or the specification of growing seasons (e.g., using GDD) by the insurance company could potentially lead to mistrust and therefore transaction costs, as there is the potential of moral hazard on the insurers' side. Cole et al. (2013) and Leblois and Quirion (2013) showed that insurance adoption increases with increasing trust in the product and the supplying institution. In summary, a straightforward index calculation that is based on data provided by a trustworthy public institution is required in order to increase market acceptance of index insurances. However, at the same time, risk reduction must be realized and basis risk must be low.

Building upon this background, our research aims to contribute to improving index-based insurance solutions by investigating the potential of publicly available information that has massive potential to reduce both geographical and temporal basis risk. More specifically, we investigated whether gridded precipitation data and locally reported vegetation phases provided (in real time and without costs) by the Deutscher Wetterdienst (DWD, the German meteorological service) improve rainfall-based index products for northern Germany. High-resolution gridded precipitation data are not only potentially valuable due to their effect on geographical basis risk, but they can also facilitate index-based insurances by providing complete and reliable long-term data series, which might not necessarily be the case for data obtained

\footnotetext{
${ }^{2}$ See also Clarke (2016) for a detailed microeconomic assessment of how basis risk affects insurance demand.
}

from a weather station. These advantages of gridded weather data also stimulated its use in other disciplines, such as in particular meteorology [see, e.g., Zolina et al. (2014) for a recent example]. Considering the abovementioned literature findings, the procedure proposed herein could reduce spatial and temporal basis risk of weather index insurance in a traceable and transparent manner. In this regard, we assume that farmers' trust in the weather index calculation is higher if the insured weather value is directly obtained from an official body rather than if the index calculation is made by the insurer.

To evaluate basis risk reduction potential, we tested two hypotheses: (i) whether WII based on grid data (denoted in the remainder of the paper as Grid) outperforms the common practice of using station data (denoted Station) and (ii) whether index accumulation based on phenological observations (denoted Phenology) outperforms monthly index accumulation (denoted Month). Risk-reducing properties are evaluated using an expected utility (EU) framework. Throughout the paper a particular emphasis was given to the consideration of the role of downside risks.

\section{Conceptual background}

\section{a. Index design}

Crop yield $y$ is a function of weather, represented by a weather index denoted as $r$. Additional factors that affect crop yields, but are uncorrelated with $r$, are summarized within the term $\varepsilon$ :

$$
y=g(r)+\varepsilon .
$$

We focus on a precipitation index in our analysis because this is a major determinant of winter wheat yield variability in our case study (see also Schillinger et al. 2008; Cabas et al. 2010). More specifically, we used a cumulative precipitation index that captures the precipitation over a specific period (Leblois et al. 2014a; Roberts et al. 2013). The calculation of this index $r_{t i}^{R}$, for year $t$ and farm $i$ is made as follows:

$$
r_{t i}^{R}=\sum_{d=\text { start }}^{\text {end }} R_{d}^{t i}
$$

where $R_{d}^{t i}$ is the precipitation at day $d$ in year $t$ relevant for farm $i$. Start and end dates are either calculated using (i) dates recorded from phenology reporters (start and end dates vary across years) or (ii) following the common practice in other approaches, where the beginning and end of months are chosen as start and end dates, respectively. 
The payout $\pi_{t}^{\text {put }}$ of the insurance contract is triggered when the weather index undercuts a certain threshold value (strike level $S_{i}$ ). Depending on the payout per missing index point (tick size $T_{i}$ ), the overall insurance payout is determined. Thus, we focus on indemnification for situations where a lack of precipitation is observed, that is, a payout structure from a European put option, defined as $\pi_{t i}^{\text {put }}=P\left\{T_{i} \max \left[\left(S_{i}-r_{t i}^{R}\right), 0\right]\right\}$ The term $T_{i}$ denotes the payout per missing millimeter of precipitation in our case study, whereas $S_{i}$ indicates the strike level of rainfall $(\mathrm{mm})$ under which the payout is triggered. The wheat price $P$ was assumed to be 15.8 Euros (EUR) per deciton (dt) (FAO 2016). Determination of $T_{i}$ and $S_{i}$ is based on the empirical relationship between wheat yields and precipitation, ${ }^{3}$ with the latter being obtained either from a weather station or for the specific location of the farm from the grid model. Here the random yield $\tilde{y}_{i}$ is stochastically dependent on the random weather index $\widetilde{r_{i}^{R}}$ and an error term $\tilde{\varepsilon}_{i}$. The yield observation can thus be decomposed as follows:

$$
\begin{aligned}
\tilde{y}_{i} & =g_{i}\left(\widetilde{r_{i}^{R}}\right)+\tilde{\varepsilon}_{i} \\
& =c_{i}+\beta_{i} r_{i}^{R}+\tilde{\varepsilon}_{i},
\end{aligned}
$$

where $\beta_{i}$ is the change in yield (slope coefficient) given a one-unit change in rainfall $r_{i}^{R}$. The term $r_{i}^{R}$ is a vector of precipitation values per farm over the years, obtained either from a weather station or out of the weather grid, whereas $c_{i}$ is an intercept.

Tick size $T_{i}$ of farm $i$ is then defined as the estimated slope coefficient $\hat{\beta}_{i}$, that is, the change in winter wheat yield given a rainfall change of $1 \mathrm{~mm}$. The term $S_{i}$ is the index value that corresponds with the mean yield ${ }^{4} \bar{y}\left[S_{i}=g_{i}^{-1}\left(\bar{y}_{i}\right)\right]$; that is, insert mean yield $\bar{y}$ together with estimates of $\hat{c}_{i}$ and $\hat{\beta}_{i}$ into Eq. (3) and solve for $r_{i}^{R}$.

We follow Conradt et al. (2015a) and estimate the parameters of Eq. (3) using quantile regression (QR). QR has been shown to be superior to the use of ordinary least squares (OLS) regression in the WII context for two reasons. First, it is more robust with respect to outliers. Second, it focuses on a particular quantile of interest, which improves the explanation of low-yield events, that is, downside risks. The estimation problem is as follows:

\footnotetext{
${ }^{3}$ We estimate this relationship for each farm separately to allow for the specification of farm-specific risk management tools.

${ }^{4}$ In contrast to the common assumption of indemnification below average rainfall levels, we follow the approach of Conradt et al. (2015a) to aim for an indemnification below average yield levels.
}

$$
\begin{aligned}
\hat{\beta}_{i}(\tau)= & \arg \min _{\beta_{i} \in \mathbb{R}}\left[\tau \sum_{y_{i} \geq \beta_{i} r_{i}^{R}}\left|y_{i}-\beta_{i} r_{i}^{R}\right|\right. \\
& \left.+(1-\tau) \sum_{y_{i}<\beta_{i} r_{i}^{R}}\left|y_{i}-\beta_{i} r_{i}^{R}\right|\right] .
\end{aligned}
$$

QR minimizes the absolute deviance rather than the squared distances between fitted value and residual. Thus, the potential influence of outliers is reduced. The parameter $\tau$ defines the quantile of interest, and the estimated relationships between winter wheat yield and rainfall index are thus quantile specific. We follow Conradt et al. (2015a) and choose $\tau=0.4,{ }^{5}$ because a special emphasis on explaining yields below this threshold is enabled by this choice $(\tau=0.5$ would focus on below-median yields in general). Hence, the insurance contract parameters $T_{i}$ and $S_{i}$ are especially suited to indemnify low yield outcomes.

The "quantreg" package (Koenker 2015) from the statistical software environment R (R Core Team 2014) was used.

\section{PRICING}

Insurance premiums $\Gamma_{i}$, are calculated separately for each farm. We consider two scenarios for the costs of the insurance. First, we use actuarially fair premiums, where the premium for each farm is equal to the expected payout from the WII. Second, we assume a loading factor of $10 \%$ in excess of this fair premium to represent other costs for the insurance. Only the former results will be presented here, as there are no differences with respect to hypotheses tests (numerical results are available in the online supplement). The fair premium is derived using a nonparametric burn rate method. To this end, a bootstrap procedure was used to obtain consistent results, where 10000 payout values were derived from random draws from the given time series of precipitation (Spicka and Hnilica 2013). ${ }^{6}$

\section{b. Expected utility framework and test strategy}

The insurance contract should lead to a reduction of the risk faced by farmers and thus should increase the

\footnotetext{
${ }^{5}$ Our results were robust against changes in $\tau$ (we tested for $\tau=0.3,0.35,0.4,0.45)$. The results of these sensitivity analyses are available upon request from the authors.

${ }^{6}$ Only weather data from the period considered in the empirical analysis of crop yields were used in favor of longer time series to prevent biases caused by nonstationarity due to climate change.
} 
utility of a risk-averse decision-maker. The riskreducing property of the insurance strongly depends on the decision-maker's risk preference. To consistently account for downside risk aversion, we use a power utility function ${ }^{7}$ (see also Berg et al. 2009; Leblois et al. 2014a). The function converts the farmer's realization of terminal wealth $W_{t i}$ (in monetary units) in year $t$ into a utility value that depends on the decision-maker's risk preferences. The expected utility of farm $i$ is the probability-weighted average of these yearly utility values (Chavas 2004).

We employ six scenarios of risk aversion in our analysis. More specifically, coefficients of relative risk aversion of $\alpha=0,0.5,1,2,3$, and 4 are inserted into the utility function, representing a gradient from risk neutrality to high risk aversion (e.g., Chavas 2004). Assuming that farmer $i$ only holds the assets' initial wealth, wheat production, and insurance, the yearly terminal wealth is equal to $W_{t i}=P y_{t i}+\pi_{t i}^{\text {put }}-\Gamma_{i}+W_{0}$, where $W_{0}$ indicates initial wealth. To empirically specify the latter, the average level of direct payments in Lower Saxony, Germany, is used (EUR $280^{8} \mathrm{ha}^{-1}$; T. Lihl, Chamber of Agriculture Lower Saxony, 2015, personal communication). Given that $W_{t i}>0$, the farmer's utility arising from a terminal wealth level $W_{t i}$ is determined as

$$
U_{i k}\left(W_{t i}\right)=\left\{\begin{array}{llc}
\frac{W_{t i}^{1-\alpha}}{1-\alpha} & \text { if } & \alpha \neq 1 \\
\ln \left(W_{t i}\right) & \text { if } & \alpha=1
\end{array} .\right.
$$

We thus obtain utility values $U_{i k}$ out of each yearly outcome $W_{t i}$, insurance product $k \in$ [Grid, Station, Phenology, Month $]^{9}$, and coefficient of relative risk aversion $\alpha$. For each farm the insurance product, the coefficient of relative risk aversion, and the average utility levels across all years are derived and are used to set up expected utility matrices $\mathbf{E U}_{i, \alpha, k}$. Each of these $|k|(=4)$ matrices contains

\footnotetext{
${ }^{7}$ See Di Falco and Chavas $(2006,2009)$ and Finger (2013) for a motivation of this functional form.

${ }^{8}$ As the power utility function implies decreasing absolute risk aversion (DARA) preferences, we tested sensitivity toward changes in the initial wealth parameter and found no qualitative differences in our results. DARA preferences imply that absolute risk aversion decreases with increasing wealth.

${ }^{9}$ The levels of $k$ denote different index underlyings, namely, Grid $\triangleq$ gridded precipitation data as described in section 3a; Station $\triangleq$ precipitation data obtained from weather station as described in section $3 \mathrm{a}$; Phenology $\triangleq$ index time frame determination using phenology observations as described in section $3 \mathrm{~b}$; and Month $\triangleq$ index time frame determination using start and end dates of months as described in section $3 \mathrm{~b}$.
}

$|i|$ (=number of farms) columns and $|\alpha|(=6)$ rows with EU values per farm and level of risk aversion.

As stated above, we subsequently test (i) $\mathbf{E U}_{i, \alpha, \text { Grid }}$ against $\mathbf{E U}_{i, \alpha, \text { Station }}$ and (ii) $\mathbf{E U}_{i, \alpha, \text { Phenology against }}$ $\mathbf{E U}_{i, \alpha, \text { Month }}$ by determining which of the insurance schemes provides the highest expected utility. Both tests are conducted across all levels of risk aversion.

Taking into account the ordinal nature of expected utility values, we use a nonparametric one-sided paired Wilcoxon rank sum test to compare the utility levels for different insurance products. As a sensitivity analysis, a nonparametrical sign test is used, which did not result in different test results.

\section{Data}

\section{a. Weather data}

All weather data were obtained from the German meteorological service (DWD), which is directed by the German public authorities. Hence, weather data are freely available for both insurer and insured. Thus, index calculation is traceable and easy to understand. Two approaches were considered for deriving precipitation data to be used as index underlying. First, the insurance is designed based on weather station data. Following Norton et al. (2012), a nearby station was allocated to each farm (in our study, the average distance between farm and weather station was $8.5 \mathrm{~km}$ ). Second, grid data were used to derive WII. To overcome the traceability issue and to ensure minimal geographical basis risk, a gridded rainfall dataset was chosen that covered the whole study period and provided immediate rainfall information for around 600000 locations in Germany. These data were derived from the gridded dataset $\mathrm{RegNie}^{10}$, which provides daily rainfall data within a grid layer of $1 \mathrm{~km} \times 1 \mathrm{~km}$ resolution. RegNie uses multiple linear regression and connects inverse distance weighted station data and orographic parameters in order to interpolate stationary measured precipitation into a grid. Further, RegNie ensures that both zero precipitation and extreme precipitation events at a weather station are not smoothed out by the values of surrounding stations but remain in the gridded data. However, zero precipitation events in between station grid cells remain difficult to predict (Rauthe et al. 2013). ${ }^{11}$ Compared to weather station data, the gridded

\footnotetext{
${ }^{10}$ The model's name RegNie stands for Regionalisierte Niederschlagshöhen (regionalized amount of precipitation).

${ }^{11}$ The overall correlation between weather station precipitation and gridded precipitation was around 0.95. However, differences were mainly due to missing dry days in the gridded dataset.
} 
TABLE 1. Comparison between precipitation values measured at weather stations and those obtained from the gridded dataset RegNie during the years 1996-2010 and 29 locations of case study farms.

\begin{tabular}{llc}
\hline \hline \multicolumn{3}{c}{ Summary statistics precipitation data } \\
\hline $\begin{array}{l}\text { Pearson correlation } \\
\text { coefficient between } \\
\text { weather station } \\
\text { data and gridded } \\
\text { precipitation data }\end{array}$ & $\begin{array}{c}\text { From shooting to ear } \\
\text { emergence }\end{array}$ & 0.96 \\
& $\begin{array}{c}\text { From ear emergence to } \\
\text { milk ripeness }\end{array}$ & 0.95 \\
$\begin{array}{l}\text { Which procedure } \\
\text { From shooting to milk } \\
\text { detected more zero } \\
\text { precipitation days }[n=435 ;\end{array}$ & 0.95 \\
$(29$ locations $\times 15$ yr $)]$ & Weather station $>$ Grid & 348 \\
\hline
\end{tabular}

dataset is less vulnerable to technical failure, as breakdowns at single stations are compensated by surrounding ones. For a more detailed explanation of the RegNie model see Rauthe et al. (2013). Detailed summary statistics of the precipitation data used are presented in the online supplement (for a summary of these statistics see Table 1 herein).

In contrast to other models used in WII applications so far (e.g., Ritter et al. 2014; World Bank 2013), this dataset is provided by an independent and public institution. The data are directly available and no further calculations are necessary, as the model provides a realtime precipitation value for each grid cell online. ${ }^{12}$

\section{b. Phenology data}

Wheat plants are sensitive to a low water supply in the growing phases of stem elongation-ear emergence, ear emergence-yellow ripeness, or stem elongationyellow ripeness ${ }^{13}$ (Farooq et al. 2012; Conradt et al. 2015b; Varga et al. 2015). To represent this sensitivity, we used two ways of designing index accumulation periods: (i) a fixed accumulation period and (ii) a flexible accumulation period based on phenology reports (Table 2).

For the fixed accumulation periods, we follow Menzel and Sparks (2006), who found that critical periods mostly occur during the periods 1 April-31 May (PM1) and 1 June-31 July (PM2), or during the whole period from 1 April to 31 July (PM1 + 2). This monthly

\footnotetext{
${ }^{12}$ We assume that a farmer's trust in the supplying institution fosters trust in a farm's individual weather value obtained from a gridded dataset.

${ }^{13}$ Note that the important growth phases of winter wheat plants take place after the winter months because plant growth is stopped at the beginning of the cold winter period and resumed afterward. Thus, winter rainfall actually has only a small effect on winter wheat growth.
}

TABLE 2. Summary statistics of accumulated precipitation across different accumulation periods. $\mathrm{CV}=$ coefficient of variation.

\begin{tabular}{llrcc}
\hline \hline \multicolumn{4}{c}{ Summary statistics precipitation (mm) during different phases } \\
\hline \multirow{4}{*}{ Period } & Mean & Std dev & CV \\
\hline \multirow{4}{*}{ Phenologly } & April-May (PM1) & 103.76 & 30.86 & 0.30 \\
& June-July (PM2) & 136.29 & 51.03 & 0.37 \\
& Stem elongation-ear & 72.34 & 35.09 & 0.51 \\
& emergence (PP1) & & & \\
& Ear emergence-milk & 71.55 & 37.65 & 0.53 \\
& ripening (PP2) & & & \\
\hline
\end{tabular}

accumulation is an often used index in the context of WII for our case study on German wheat production (Heimfarth et al. 2012; Pelka and Musshoff 2013).

For the flexible index accumulation window, phenological observations are used. More specifically, the DWD provides a "phenological observation network" for a variety of plants consisting of about 1200 locations all over Germany (Deutsche Wetterdienst 1991, p. 151). "Phenological yearly reporters" observe a reference field ${ }^{14}$ and capture a phenological phase, when about $50 \%$ of all plants reach it. Reporting is done by a volunteer who reports the growth stage occurrence of different plants around his reporting location. ${ }^{15}$ For a detailed explanation of the reporting procedure and plants observed see Kaspar et al. (2014). For winter wheat, the observed and reported phases are (i) tilling, (ii) seedling growth, (iii) stem elongation, (iv) ear emergence, (v) milk ripeness, (vi) yellow ripeness, and (vii) harvest. We used this phenological reporters' data to determine the calendar dates of above-watersensitive winter wheat growing stages. Specifically, phases III to IV (PP1), IV to V (PP2), or III to V (PP1 + 2) are utilized. We matched the appropriate location of a reporter to a specific farm using GIS information of phenological regions as defined by Ssymank (1994) ${ }^{16}$ Concerning both the fixed and the flexible determinations, we considered possible farm-specific differences in the accumulation period. More specifically we chose the rainfall accumulation period farm individually by utilizing the one providing the highest EU increase per farm from the three possible periods. Thus, for both monthly and phenology stage accumulated indices, three insurance products are offered to the farmer, namely, PM1, PM2, or PM1 + 2 for

\footnotetext{
${ }^{14}$ Note that the observed sites are cultivated under practical, nonexperimental conditions.

${ }^{15}$ A reviewer indicated that this could give incentives to insured farmers to influence the reporters to provoke insurance payouts, which should be considered if implementing the methodology proposed here.

${ }^{16}$ See the online supplement for a GIS map of these regions.
} 


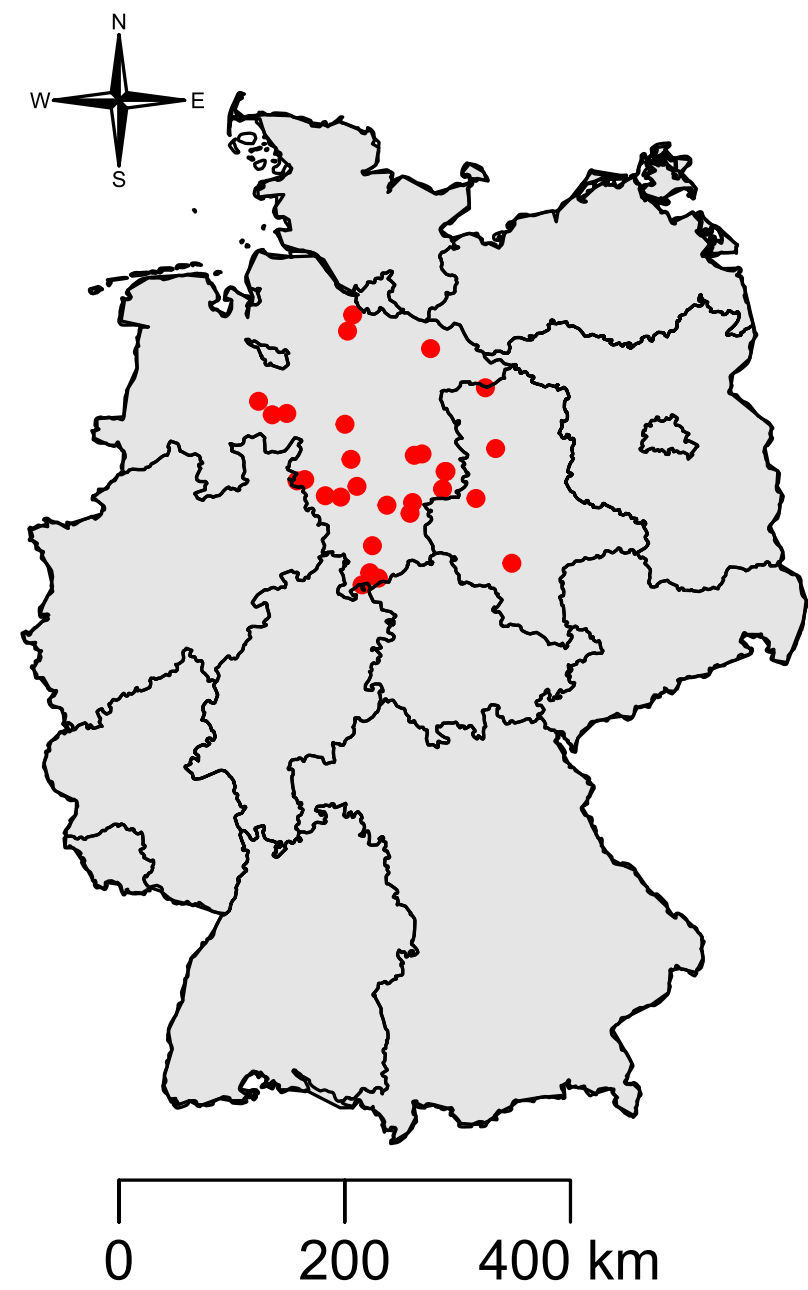

FIG. 1. Location of case study farms. Farms are presented as red points (Heimfarth et al. 2012; Pelka and Musshoff 2013).

monthly and PP1, PP2, or PP1 +2 for phenology accumulation dates. We further assume that a farmer chooses the WII insurance product that provides the highest EU value for his or her farm. Consequently, we obtain two optimal accumulation periods per farm, one for monthly and one for phenology phase accumulation indices. ${ }^{17}$

For detailed summary statistics of rainfall during the different accumulation periods, see the sections "Monthly Precipitation" and "Phenology Phase Precipitation" in the online supplement. It should be noted that the variation in rainfall is considerably higher in the phenology phase accumulated dataset compared to the monthly accumulated precipitation (see Table 2).

\footnotetext{
${ }^{17}$ We indicated optimal phases in the "Accumulation Phase" section of the online supplement.
}

TABLE 3. Summary statistics of wheat yields of case study farms in northern Germany.

\begin{tabular}{llr}
\hline \multicolumn{3}{c}{ Summary statistics yield data } \\
\hline No. of farms & 29 \\
Min & $\left(\mathrm{dt} \mathrm{ha}^{-1}\right)$ & 45.51 \\
Max & $\left(\mathrm{dt} \mathrm{ha}^{-1}\right)$ & 132.00 \\
Mean & $\left(\mathrm{dt} \mathrm{ha}^{-1}\right)$ & 86.91 \\
Median & $\left(\mathrm{dt} \mathrm{ha}^{-1}\right)$ & 86.00 \\
Std dev & $\left(\mathrm{dt} \mathrm{ha}^{-1}\right)$ & 14.47 \\
CV & & 0.17
\end{tabular}

\section{c. Study area and yield dataset}

Winter wheat panel data were available from 1996 to 2010 for 29 farms in the southeastern part of the federal states of Lower Saxony and Saxony-Anhalt. ${ }^{18}$ The locations of farms are presented in Fig. 1. Crop production, particularly winter wheat, is an important part of a farm's portfolio in this region (Lower Saxony Ministry of Food, Agriculture, Consumer Protection and Regional Development 2011). The average farm size in the study area is around 60 ha (Heimfarth et al. 2012) with podzols and luvisols being predominant soil types. The yield data have been provided by Pelka and Musshoff (2013) in detrended form. The detrending to control for technological change conducted by Pelka and Musshoff (2013) was based on linear regressions as motivated by Heimfarth et al. (2012). ${ }^{19}$ The yield data are summarized in Table 3. The mean annual precipitation within the study period is $710 \mathrm{~mm}$, and precipitation is characterized by high volatility with an average standard deviation of $154 \mathrm{~mm}$ across all the stations considered in our analysis.

\section{Results}

Compared to a situation without insurance, all the insurance products that were tested showed an EU increase that was significantly greater than zero. Tick sizes, strike levels, premiums, number of payouts within 15 years, and optimal accumulation periods are documented in detail in the online supplement. Table 4 summarizes the option parameters for a coefficient of relative risk aversion equal to one. The very high

\footnotetext{
${ }^{18}$ Note that farms within the panel have neither indemnity- nor index-based insurance protection during the investigation period. We thus assume that cultivation decisions are made based on good agricultural practice with no incentives to produce at lower cost, as there is no protection against low-yield outcomes.

${ }^{19}$ In Heimfarth et al. (2012), different regression approaches have been considered, that is, linear and quadratic trend models, as well as OLS and robust regression approaches (Finger 2010).
} 
TABLE 4. Summary statistics of insurance contract parameters for $\alpha=1$ across all 29 case study farms.

\begin{tabular}{|c|c|c|c|}
\hline Data source & Grid and Phenology & Station and Phenology & Station and Months \\
\hline \multicolumn{4}{|l|}{ Strike level (mm precipitation $\mathrm{m}^{-2}$ ) } \\
\hline Median & 112.16 & 113.10 & 244.83 \\
\hline Min & 24.93 & -3.21 & 59.22 \\
\hline Max & 255.24 & 244.83 & 3151.06 \\
\hline \multicolumn{4}{|l|}{ Price $\left(\right.$ EUR ha $\left.{ }^{-1}\right)$} \\
\hline Median & 42.18 & 51.51 & 38.46 \\
\hline Min & 1.01 & 0.00 & 0.02 \\
\hline Max & 101.08 & 118.68 & 80.50 \\
\hline \multicolumn{4}{|c|}{ Average number of positive net payouts (payout minus premium; out of 15 years) } \\
\hline Mean & 5.21 & 5.38 & 5.45 \\
\hline \multicolumn{4}{|l|}{ Optimal accumulation period ${ }^{\mathrm{a}}$} \\
\hline Period 1 & 13 & 16 & 6 \\
\hline Period 2 & 5 & 5 & 6 \\
\hline Periods $1+2$ & 8 & 7 & 12 \\
\hline Number of insured out of 29 farms $^{b}$ & 26 & 28 & 24 \\
\hline
\end{tabular}

${ }^{a}$ Note that the definition for period is different for fixed and flexible indices. See section $3 b$ for further details.

${ }^{\mathrm{b}}$ Note that we assumed the insurance contract to be concluded only if the slope coefficient of QR is positive.

maximum $\left(7359.70 \mathrm{~mm} \mathrm{~m}^{-2}\right)$ and very low minimum $\left(-3.21 \mathrm{~mm} \mathrm{~m}^{-2}\right)$ values in the strike-level section reflect cases of poor quantile regression results with respect to the estimates of intercept and slope coefficient. ${ }^{20}$ In our analysis we focus on put options, reflecting that a lack of rainfall causes yield losses, and thus we assume that farmers insure only if the slope coefficient of the regression is positive. Based on this exclusion criterion, the combination of station rainfall and flexible adjusted periods resulted in 28 out of 29 possible farmers being insured, whereas "Grid and Phenology" and "Station and Months" result in 26 and 24 contracts, respectively (Table 4).

Recalling the abovementioned description of the test procedure, we tested the following null hypotheses:

(i) The EU of farmers insured using gridded precipitation data is greater than or equal to the $\mathbf{E U}$ of insured farmers using precipitation data obtained from nearby weather stations (denoted as $\mathbf{E U}_{\text {Grid }} \geq$ $\left.\mathbf{E U}_{\text {Station }}\right)$.

(ii) The EU of farmers insured via flexible rainfall accumulation period determined using phenological observations is less than or equal to that of farmers insured using monthly accumulated precipitation (denoted as $\mathbf{E U}_{\text {Month }} \geq \mathbf{E U}_{\mathrm{Phen}}$ ).

The results of test procedures are displayed in Table 5. In contrast to our expectation, we find that using gridded

\footnotetext{
${ }^{20}$ However, because the insurance payouts resulting from these contract specifications were either zero or very low, and the overall results remained unaffected by the exclusion of these cases, we kept these observations in the sample of our analysis.
}

precipitation data as provided by DWD in designing weather index insurance did not lead to a higher EU for farmers in our example. This result holds for all levels of risk aversion considered. In contrast, implementing phenological observations significantly contributed to an EU increase for risk-averse farmers. Thus, we can reject the null hypothesis for all levels of risk aversion greater than zero, supporting the alternative hypothesis that the EU of index-insured farmers using flexible rainfall accumulation periods determined using phenological observations is greater than the EU of index-insured farmers using fixed monthly rainfall accumulation periods.

\section{Discussion and conclusions}

In this paper we present the first study that tests the performance of gridded precipitation data and phenological observations provided by a public body in a WII framework. For our case study, we reject the hypothesis that precipitation grid data reduce spatial basis risk. Two reasons are expected to cause this result. First, the rainfall interpolation model underestimates the occurrence of dry days and therefore low rainfall risks (Fosser 2013). ${ }^{21}$ Second, the weather station density was rather high in our sample, as the mean distance between farm and station location was $8.5 \mathrm{~km}$ with a minimum of $0.45 \mathrm{~km}$ and a maximum of $18 \mathrm{~km}$. Despite this result,

\footnotetext{
${ }^{21}$ Also in our dataset in $80 \%$ of the observations, the gridded dataset detected fewer zero precipitation days than the weather station dataset.
} 
TABLE 5. Results of Wilcoxon tests: Basis risk reduction due to using gridded precipitation and phenological reporters' data.

\begin{tabular}{lccc}
\hline \hline $\begin{array}{c}\text { Coefficient of } \\
\text { relative risk } \\
\text { aversion } r_{r}\end{array}$ & $H_{0}: \mathbf{E U}_{\text {Grid }} \geq \mathbf{E U}_{\text {Station }}$ & & $H_{0}: \mathbf{E U}_{\text {Month }} \geq \mathbf{E U}_{\text {Phen }}$ \\
(risk neutral) & $p$ value & & Wilcoxon rank test \\
0.5 & 0.53 & 0.12 \\
1 & 0.40 & $2.9 \times 10^{-3}$ \\
2 & 0.35 & $1.4 \times 10^{-4}$ \\
3 & 0.34 & $2.5 \times 10^{-4}$ \\
4 (extremely & 0.38 & $8.9 \times 10^{-4}$ \\
$\quad$ risk averse) & 0.47 & $1.6 \times 10^{-3}$ \\
\hline
\end{tabular}

two important advantages of grid data must be highlighted for practical implementation. First, using grid data, it is no longer necessary to find an appropriate weather station. Second, the time series of grid data weather information is always complete and technical failure is less likely, as the underlying grid model excludes data gaps of affected stations. Based on these aspects, future research should develop institutionally provided grid data that are especially designed for insurance practice. Providing such data to the local insurance industry could significantly increase the attractiveness of WII products, without providing premium subsidies.

In line with our initial hypothesis, we find that the use of phenological observations significantly reduces basis risk. The finding that accounting for growing phases improves WII performance is in line with the recent findings of Conradt et al. (2015b). Our results, however, also made use of a rich available pool of reported phenological observations that has not yet been considered in weather index insurance research. The utility gains identified in our analysis reveal potential benefits for both farmers and insurance companies. Thus, phenological observations should be included in weather index insurance practice, especially in view of their relevance in crop science (Olesen et al. 2012). However, further approaches to find occurrence dates of growth stages could be tested in the WII context, such as satellite imagery (Vrieling et al. 2013) or weather data (Saiyed et al. 2009).

Based on our results and in view of these data sources becoming increasing availabile in countries other than Germany [MeteoSwiss 2011, 2016; USA National Phenology Network (2016) for example in Switzerland and the United States], as well as the increasing availability of satellite data (de Leeuw et al. 2014), there is a high potential for improvements in WII solutions. Further research should take into account additional datasets that combine interpolation and radar observations into a grid layer, as this methodology increases accuracy in extreme event estimation [Radar Online Adjustment (RADOLAN) for Germany; ftp://ftp. dwd.de/pub/CDC/grids_germany/daily/radolan/]. Moreover, these datasets can stimulate the further development of index insurance at the farm level, as there is a tendency in index insurance literature to concentrate on the "meso" level or agribusiness firms instead of focusing on single farms (Miranda and Gonzalez-Vega 2010; Farrin and Miranda 2015; Weber et al. 2015).

Acknowledgments. We thank the Deutscher Wetterdienst for providing weather and phenology data, Oliver Musshoff for the provision of the winter wheat yield data, and the Bundesamt für Naturschutz for providing GIS maps of phenological regions. We are grateful for the comments made by four anonymous reviewers on an earlier draft of this paper.

\section{REFERENCES}

Berg, A., P. Quirion, and B. Sultan, 2009: Weather-index drought insurance in Burkina-Faso: Assessment of its potential interest to farmers. Wea. Climate Soc., 1, 71-84, doi:10.1175/ 2009WCAS1008.1.

Berg, E., and B. Schmitz, 2008: Weather-based instruments in the context of whole-farm risk management. Agric. Finance Rev., 68, 119-133, doi:10.1108/00214660880001222.

Cabas, J., A. Weersink, and E. Olale, 2010: Crop yield response to economic, site and climatic variables. Climatic Change, 101, 599-616, doi:10.1007/s10584-009-9754-4.

Chavas, J.-P., 2004: Risk Analysis in Theory and Practice. Advanced Finance Series, Academic Press, 247 pp.

Clarke, D. J., 2016: A theory of rational demand for index insurance. Amer. Econ. J.: Microeconomics, 8, 283-306, doi:10.1257/ mic. 20140103.

Cole, S., X. Giné, J. Tobacman, R. Townsend, P. Topalova, and J. Vickery, 2013: Barriers to household risk management: Evidence from India. Amer. Econ. J.: Appl. Econ., 5, 104-135, doi:10.1257/app.5.1.104.

Conradt, S., R. Finger, and R. Bokusheva, 2015a: Tailored to the extremes: Quantile regression for index-based insurance contract design. Agric. Econ., 46, 537-547, doi:10.1111/ agec. 12180

,-- , and M. Spörri, 2015b: Flexible weather index-based insurance design. Climate Risk Manage., 10, 106-117, doi:10.1016/ j.crm.2015.06.003.

de Leeuw, J., A. Vrieling, A. Shee, C. Atzberger, K. Hadgu, C. Biradar, H. Keah, and C. Turvey, 2014: The potential and uptake of remote sensing in insurance: A review. Remote Sens., 6, $10888-10912$, doi:10.3390/rs61110888.

Deng, X., B. J. Barnett, D. V. Vedenov, and J. W. West, 2007: Hedging dairy production losses using weather-based index insurance. Agric. Econ., 36, 271-280, doi:10.1111/ j.1574-0862.2007.00204.x.

Deutscher Wetterdienst, 1991: Anleitung für phänologischen Beobachter des Deutschen Wetterdienstes. 3rd ed. Vorschriften und Betriebsunterlagen, Vol. 17, DWD, 155 pp.

Díaz-Nieto, J., S. E. Cook, P. Läderach, M. J. Fisher, and P. G. Jones, 2010: Rainfall index insurance to help smallholder 
farmers manage drought risk. Climate Dev., 2, 233-247, doi:10.3763/cdev.2010.0050.

Di Falco, S., and J.-P. Chavas, 2006: Crop genetic diversity, farm productivity and the management of environmental risk in rainfed agriculture. Eur. Rev. Agric. Econ., 33, 289-314, doi:10.1093/eurrag/jbl016.

$\longrightarrow$, and - 2009: On crop biodiversity, risk exposure, and food security in the highlands of Ethopia. Amer. J. Agric. Econ., 91, 599-611, doi:10.1111/j.1467-8276.2009.01265.x.

Elabed, G., M. F. Bellemare, M. R. Carter, and C. Guirkinger, 2013: Managing basis risk with multiscale index insurance. Agric. Econ., 44, 419-431, doi:10.1111/agec.12025.

FAO, 2016: FAOSTAT statistical database. Accessed 30 August 2016. [Available online at http://faostat.fao.org/.]

Farooq, M., M. Hussain, A. Wahid, and K. H. M. Siddique, 2012: Drought stress in plants: An overview. Plant Responses to Drought Stress: From Morphological to Molecular Features, R. Aroca, Ed., Springer, 1-33, doi:10.1007/978-3-642-32653-0_1.

Farrin, K., and M. J. Miranda, 2015: A heterogeneous agent model of credit-linked index insurance and farm technology adoption. J. Dev. Econ., 116, 199-211, doi:10.1016/ j.jdeveco.2015.05.001.

Finger, R., 2010: Revisiting the evaluation of robust regression techniques for crop yield data detrending. Amer. J. Agric. Econ., 92, 205-211, doi:10.1093/ajae/aap021.

$\ldots$, 2013: Expanding risk consideration in integrated modelsThe role of downside risk aversion in irrigation decisions. Environ. Modell. Software, 43, 169-172, doi:10.1016/ j.envsoft.2013.02.001.

Fosser, G., 2013: Precipitation statistics from regional climate model at resolutions relevant for soil erosion. Ph.D. dissertation, Karlsruhe Institute of Technology, 177 pp., doi:10.5445/ $\mathrm{KSP} / 1000041271$

Gine, X., R. Townsend, and J. Vickery, 2008: Patterns of rainfall insurance participation in rural India. World Bank Econ. Rev., 22, 539-566, doi:10.1093/wber/lhn015.

Glauber, J. W., 2013: The growth of the Federal Crop Insurance Program, 1990-2011. Amer. J. Agric. Econ., 95, 482-488, doi:10.1093/ajae/aas091.

Hardaker, J. B., R. B. M. Huirne, J. R. Anderson, and G. Lien, 2004: Coping with Risk in Agriculture. 2nd ed. CABI Publishing, $332 \mathrm{pp}$.

Heimfarth, E. L., and O. Musshoff, 2011: Weather index-based insurances for farmers in the North China Plain: An analysis of risk reduction potential and basis risk. Agr. Finance Rev., 71, 218-239, doi:10.1108/00021461111152582.

_- R. Finger, and O. Musshoff, 2012: Hedging weather risk on aggregated and individual farm-level: Pitfalls of aggregation biases on the evaluation of weather index-based insurance. Agr. Finance Rev., 72, 471-487, doi:10.1108/ 00021461211277295

Kapphan, I., P. Calanca, and A. Holzkaemper, 2012: Climate change, weather insurance design and hedging effectiveness. Geneva Pap. Risk Insur.: Issues Pract., 37, 286-317, doi:10.1057/ gpp.2012.8.

Kaspar, F., K. Zimmermann, and C. Polte-Rudolf, 2014: An overview of the phenological observation network and the phenological database of Germany's national meteorological service (Deutscher Wetterdienst). Adv. Sci. Res., 11, 93-99, doi:10.5194/asr-11-93-2014.

Koenker, R., 2015: quantreg: Quantile regression, version 5.11. R package. [Available online at http://CRAN.R-project.org/ package $=$ quantreg.]
Kumar, V. P., V. U. M. Rao, O. Bhavani, A. P. Dubey, C. B. Singh, and B. Venkateswarlu, 2016: Sensitive growth stages and temperature thresholds in wheat (Triticum aestivum L.) for index-based crop insurance in the Indo-Gangetic Plains of India. J. Agric. Sci., 154, 321-333, doi:10.1017/ S0021859615000209.

Leblois, A., and P. Quirion, 2013: Agricultural insurances based on meteorological indices: Realizations, methods and research challenges. Meteor. Appl., 20, 1-9, doi:10.1002/met.303.

- _ - A. Alhassane, and S. Traoré, 2014a: Weather index drought insurance: An ex ante evaluation for millet growers in Niger. Environ. Resour. Econ., 57, 527-551, doi:10.1007/ s10640-013-9641-3.

—_ — - and B. Sultan, 2014b: Price vs. weather shock hedging for cash crops: Ex ante evaluation for cotton producers in Cameroon. Ecol. Econ., 101, 67-80, doi:10.1016/ j.ecolecon.2014.02.021.

Lower Saxony Ministry of Food, Agriculture, Consumer Protection and Regional Development, 2011: Die niedersächsische Landwirtschaft in Zahlen. Rep. 107, Niedersachsen, 82 pp.

Menzel, A., and T. Sparks, 2006: Temperature and plant development: Phenology and seasonality. Plant Growth and Climate Change, J. I. L. Morison and M. D. Morecroft, Eds., Wiley-Blackwell, 70-95.

MeteoSwiss, 2011: MeteoSwiss grid-data products: Documentation for users. Accessed 8 January 2016, 4 pp. [Available online at https://www1.ethz.ch/ifu/hydrologie/research/research_data/ proddoc.pdf.]

__ 2016: Phänologisches Beobachtungsnetz. Accessed 8 January 2016. [Available online at http://www.meteoschweiz. admin.ch/home/mess-und-prognosesysteme/bodenstationen/ phaenologisches-beobachtungsnetz.html.]

Miranda, M. J., and C. Gonzalez-Vega, 2010: Systemic risk, index insurance, and optimal management of agricultural loan portfolios in developing countries. Amer. J. Agric. Econ., 93, 399-406.

Norton, M. T., C. Turvey, and D. Osgood, 2012: Quantifying spatial basis risk for weather index insurance. J. Risk Finance, 14, 20-34, doi:10.1108/15265941311288086.

— S. Boucher, and L. Verteramo Chiu, 2015: Geostatistics, basis risk and weather index insurance. Proc. 2015 Agricultural and Applied Economics Association and Western Agricultural Economics Association Annual Meeting, San Francisco, CA, Agricultural and Applied Economics Association. [Available online at http://ageconsearch.umn.edu/bitstream/205755/2/ Norton_AAEA_2015.pdf.]

Odening, M., and Z. Shen, 2014: Challenges of insuring weather risk in agriculture. Agric. Finance Rev., 74, 188-199, doi:10.1108/AFR-11-2013-0039.

— O. Musshoff, and W. Xu, 2007: Analysis of rainfall derivatives using daily precipitation models: Opportunities and pitfalls. $A g$ ric. Finance Rev., 67, 135-156, doi:10.1108/00214660780001202.

Olesen, J. E., and Coauthors, 2012: Changes in time of sowing, flowering and maturity of cereals in Europe under climate change. Food Addit. Contam., 29A, 1527-1542, doi:10.1080/ 19440049.2012.712060.

Patt, A., N. Peterson, M. Carter, M. Velez, U. Hess, and P. Suarez, 2009: Making index insurance attractive to farmers. Mitigation Adapt. Strategies Global Change, 14, 737-753, doi:10.1007/ s11027-009-9196-3.

Paulson, N. D., C. E. Hart, and D. J. Hayes, 2010: A spatial Bayesian approach to weather derivatives. Agric. Finance Rev., 70, 79-96, doi:10.1108/00021461011042657. 
Pelka, N., and O. Musshoff, 2013: Hedging effectiveness of weather derivatives in arable farming-Is there a need for mixed indices? Agric. Finance Rev., 73, 358-372, doi:10.1108/ AFR-10-2012-0055.

Rauthe, M., H. Steiner, U. Riediger, A. Mazurkiewicz, and A. Gratzki, 2013: A Central European precipitation climatology-Part I: Generation and validation of a high-resolution gridded daily data set (HYRAS). Meteor. Z., 22, 235-256, doi:10.1127/ 0941-2948/2013/0436.

R Core Team, 2014: R: A language and environment for statistical computing. R Foundation for Statistical Computing. [Available online at http://www.R-project.org/.]

Ritter, M., O. Musshoff, and M. Odening, 2014: Minimizing geographical basis risk of weather derivatives using a multi-site rainfal model. Comput. Econ., 44, 67-86, doi:10.1007/s10614-013-9410-y.

Roberts, M. J., W. Schlenker, and J. Eyer, 2013: Agronomic weather measures in econometric models of crop yield with implications for climate change. Amer. J. Agric. Econ., 95 236-243, doi:10.1093/ajae/aas047.

Saiyed, I. M., P. R. Bullock, H. D. Sapirstein, G. J. Finlay, and C. K. Jarvis, 2009: Thermal time models for estimating wheat phenological development and weather-based relationships to wheat quality. Can. J. Plant Sci., 89, 429-439, doi:10.4141/CJPS07114.

Schillinger, W. F., S. E. Schofstoll, and J. R. Alldredge, 2008: Available water and wheat grain yield relations in a Mediterranean climate. Field Crops Res., 109, 45-49, doi:10.1016/ j.fcr.2008.06.008.

Spicka, J., and J. Hnilica, 2013: A methodical approach to design and valuation of weather derivatives in agriculture. $A d v$. Meteor., 2013, 146036, doi:10.1155/2013/146036.

Ssymank, A., 1994: Neue Anforderungen im europäischen Naturschutz: Das Schutzgebietssystem Natura 2000 und die FFHRichtlinie der EU. Natur Land, 69, 395-406.
Turvey, C. G., 2001: Weather derivatives for specific event risks in agriculture. Rev. Agric. Econ., 23, 333-351, doi:10.1111/ 1467-9353.00065.

— , and M. K. McLaurin, 2012: Applicability of the normalized difference vegetation index (NDVI) in index-based crop insurance design. Wea. Climate Soc., 4, 271-284, doi:10.1175/ WCAS-D-11-00059.1.

USA National Phenology Network, 2016: Phenology data overview. [Available online at https://www.usanpn.org/ data.]

Varga, B., G. Vida, E. Varga-László, S. Bencze, and O. Veisz, 2015: Effect of simulating drought in various phenophases on the water use efficiency of winter wheat. J. Agron. Crop Sci., 201, 1-9, doi:10.1111/jac.12087.

Vrieling, A., J. de Leeuw, and M. Y. Said, 2013: Length of growing period over Africa: Variability and trends from 30 years of NDVI time series. Remote Sens., 5 (2), 982-1000, doi:10.3390/ rs5020982.

Weber, R., W. Fecke, I. Moeller, and O. Musshoff, 2015: Mesolevel weather index insurance. Agric. Finance Rev., 75, 31-46, doi:10.1108/AFR-12-2014-0045.

Woodard, J. D., and P. Garcia, 2008: Basis risk and weather hedging effectiveness. Agric. Finance Rev., 68, 99-117, doi:10.1108/ 00214660880001221.

World Bank, 2013: Weather data grids for agriculture risk management: The case of Honduras and Guatemala. Rep. 77780, 34 pp. [Available online at https://openknowledge.worldbank.org/ handle/10986/16501.]

Zolina, O., C. Simmer, A. Kapala, P. Shabanov, P. Becker, H. Mächel, S. Gulev, and P. Groisman, 2014: Precipitation variability and extremes in central Europe: New view from STAMMEX results. Bull. Amer. Meteor. Soc., 95, 995-1002, doi:10.1175/BAMS-D-12-00134.1. 